\title{
Prognostic Significance of Thrombocytosis in Patients with Locally Advanced Cervical Carcinoma Treated with Chemoradiotherapy
}

\author{
Nanda Ramanand ${ }^{1}$, Shamsundar Sunkappa Dayashankara ${ }^{1,}{ }^{*}$, Aradhana Katke ${ }^{1}$ and Thejaswini \\ Boraiah $^{1}$ \\ ${ }^{1}$ Radiation Oncology, Kidwai Cancer Institute, Bangalore, India \\ Corresponding author: Radiation Oncology, Kidwai Cancer Institute, Bangalore 560029, India. Email: shamsundar_sd@yahoo.co.in
}

Received 2018 October 15; Revised 2019 January 18; Accepted 2019 January 24.

\begin{abstract}
Background: The outcome of chemoradiotherapy in patients with locally advanced cervical carcinoma is highly variable and depends on various prognostic factors.

Objectives: The aim of this study is to evaluate the prevalence and prognostic significance of thrombocytosis in this group of the patients referred to our institution.

Methods: Between January 2008 and December 2012, 195 patients with locally advanced cervical carcinoma (International Federation of Gynecology and Obstetrics (FIGO) stages of IIB-IIIB), treated with external beam radiotherapy (EBRT) to a dose of 45 Gy in 25 fractions along with concurrent chemotherapy (cisplatin $40 \mathrm{mg} / \mathrm{m}^{2}$ ), followed by HDR brachytherapy EQD2 of $30 \mathrm{~Gy}$. The platelet counts were recorded pre-treatment and during treatment in all the patients.

Results: Among the 195 patients, 101 (51.5\%) belonged to stage IIB and 94 (48.5\%) to stage IIIB. Thrombocytosis (platelet count > 400 $\times 10^{9}$ /liter) was seen in $31(15.8 \%)$ patients. The overall survival in thrombocytosis group is $41 \%$, which is significantly less than the overall survival of the non-thrombocytosis group, which is $62 \%$.

Conclusions: Thrombocytosis is not a frequent finding in patients with locally advanced cervical carcinoma in our population; however, when it is present, it is associated with poor outcome in terms of survival.
\end{abstract}

Keywords: Thrombocytosis, Cervical Carcinoma, Platelet Count, Outcome

\section{Background}

The association between thrombocytosis and malignancies has been known for over a century (1). Numerous studies have been carried out to evaluate thrombocytosis as a prognostic marker (2-8). Thrombocytosis is associated with various gynecological and non-gynecological cancers, especially in thoracic and gastrointestinal malignancies $(2,3,6)$. Malignancy-related thrombocytosis is seen in about $4 \%$ to $55 \%$ of the patients, in particular, more in the advanced stages (9).

Most studies that have investigated the prognostic implications of thrombocytosis in patients with cervical cancer have yielded contradictory results; few have shown positive correlation while others found no such correlation (4, $5,10-16)$. India has the largest burden of cervical cancer but there is a lack of studies regarding the incidence of thrombocytosis and its correlation with response and survival.

\section{Objectives}

We have performed the present study to investigate the incidence and prognostic significance of thrombocytosis in patients with cervical cancer, treated with definitive chemoradiotherapy.

\section{Methods}

Between January 2008 and December 2012,195 patients with locally advanced cervical cancer (International Federation of Gynaecology and Obstetrics [FIGO] stages IIBIIIB) were treated with external beam radiotherapy (EBRT) with a dose of $45 \mathrm{~Gy}$ in 25 fractions, on cobalt 60, along with weekly concurrent cisplatin. High dose rate (HDR) brachytherapy, to a dose of $7 \mathrm{~Gy}$ in 3 fractions, was delivered either by intracavitary or interstitial brachytherapy. All patients included in the study had completed the planned radiation. 
The response to the treatment was assessed 3 months post-treatment in accordance with response evaluation criteria in solid tumors (RECIST). Patients underwent periodic detailed clinical evaluation and imaging (computerized tomography scan) during the follow-up period.

Thrombocytosis was defined as a platelet count greater than $400 \times 10^{9}$ /liter on at least 2 separate occasions. Blood tests of all the patients were carried out, including complete blood count at the time of diagnosis and before the start of chemoradiation. Patients who had a previous history of cancer or predisposing conditions to thrombocytosis such as a history of splenectomy, rheumatoid disease, myeloproliferative disorders, acute inflammatory disease, and a history of malignancy were excluded from the study.

\subsection{Statistical Analysis}

This is a retrospective analytical study. The KaplanMeier method was used for determining the overall survival (OS) and disease-free survival (DFS). Statistical significance was defined as a probability value of $\leq 0.05$. The significance of potential prognostic factors was assessed by the Cox proportional hazards model. The SPSS software version 15 was used for statistical analysis.

\section{Results}

In this study, 195 patients were divided into two groups based on their platelet counts. The patients having a platelet count greater than $400 \times 10^{9} /$ liter were placed in the thrombocytosis group at presentation (31 patients, $15.8 \%$ ) and those with platelet counts less than $400 \times$ $10^{9}$ /liter were placed in the non-thrombocytosis group (164 patients, $84.2 \%$ ). The patient characteristics in both groups are summarized in Table 1.

The mean age of the entire retrospective study was 45 years. The total number of patients with stage II and stage III disease was 101 and 94, respectively and they were comparable in both groups. The hemoglobin level at presentation was more than $10 \mathrm{~g} / \mathrm{dL}$ in 167 patients in comparison to 28 patients who had levels less than $10 \mathrm{~g} / \mathrm{dL}$. Concurrent chemotherapy with weekly cisplatin to a cumulative dose of $250 \mathrm{mg}$ or more was received by 113 patients in the nonthrombocytosis and 21 patients in thrombocytosis group. The response to treatment was evaluated clinically and by imaging.

In the non-thrombocytosis group, 131 patients showed complete or partial response and 33 had stable or progressive disease. In the thrombocytosis group, 15 patients showed complete or partial response and 16 patients had stable or progressive disease. This study shows a significant association between platelet levels at diagnosis and the response to treatment ( $\mathrm{P}$ value $<0.001$ ). The 5-yearOS in the non-thrombocytosis group was higher (62\%) than the thrombocytosis group (41\%); similarly, the 5-year DFS was $61 \%$ and $39 \%$, respectively. The OS and DFS had statistical significance in both arms ( $P$ value $<0.001$ ) across platelet counts at diagnosis (Figures 1 and 2). In multivariate analysis, platelet counts greater than $400 \times 10^{9} /$ liter and age less than 45 years had poor survival and other factors didn't show any significance (Table 2).

\section{Discussion}

Few studies on cervical cancer have assessed thrombocytosis as a prognostic indicator in patients receiving chemoradiation $(5,10-16)$. Two studies conducted by

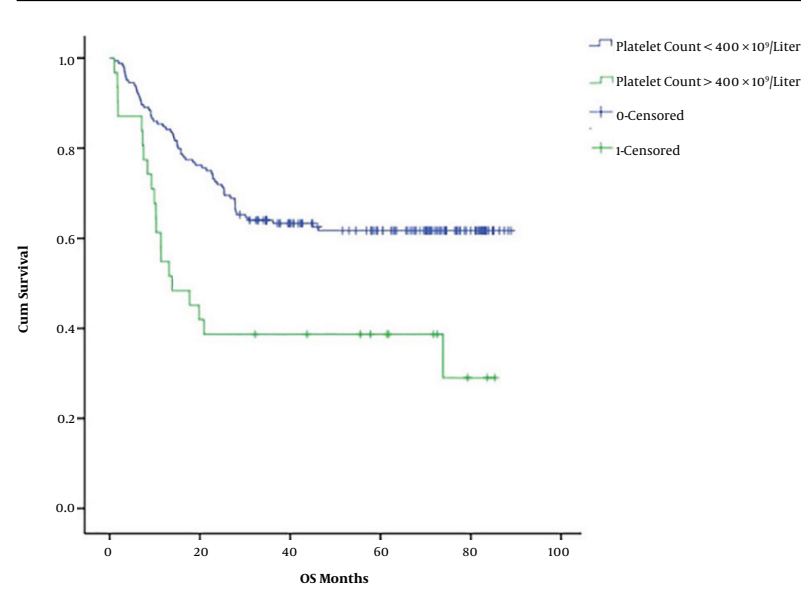

Figure 1. Overall survival of thrombocytosis and non-thrombocytosis groups

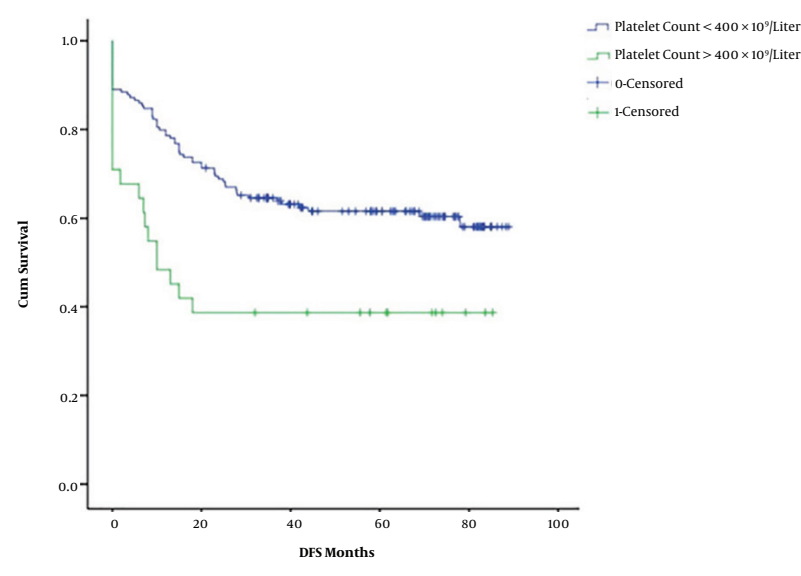

Figure 2. Disease free survival of thrombocytosis and non-thrombocytosis groups 


\begin{tabular}{|c|c|c|c|c|c|}
\hline Characteristics & All Patients (195) & Patients Without Thrombocytosis (164) & \multicolumn{2}{|c|}{ Patients with Thrombocytosis (31) } & P Value \\
\hline \multicolumn{5}{|l|}{ Age, $y$} & 0.721 \\
\hline Mean & 45 & 45 & & 44 & \\
\hline$<45$ & 113 & 93 & & 20 & \\
\hline$>45$ & 82 & 71 & & 11 & \\
\hline \multicolumn{5}{|l|}{ Stage } & 1.009 \\
\hline II & 101 & 85 & & 16 & \\
\hline III & 94 & 79 & & 15 & \\
\hline \multicolumn{5}{|l|}{ Heamaglobin, g/dL } & 0.401 \\
\hline$<10$ & 28 & 20 & & 8 & \\
\hline$>10$ & 167 & 144 & & 23 & \\
\hline \multicolumn{5}{|l|}{ Cumulative cisplatin dose, $\mathrm{mg}$} & 0.441 \\
\hline$\leq 250$ & 134 & 113 & & 21 & \\
\hline$>250$ & 61 & 51 & & 10 & \\
\hline \multicolumn{5}{|l|}{ Treatment response } & 0.001 \\
\hline Partial or complete response & 146 & 131 & & 15 & \\
\hline Stable or progressive disease & 49 & 33 & & 16 & \\
\hline \multirow{2}{*}{ Variable } & & \multirow{2}{*}{ PValue } & \multicolumn{3}{|c|}{ 0.95\% Confidence Interval } \\
\hline & & & Lower & Upper & \\
\hline \multicolumn{6}{|l|}{ Age group } \\
\hline \multicolumn{2}{|l|}{$<45$ years vs. $>45$ years } & 0.006 & 2.503 & \multicolumn{2}{|l|}{233.106} \\
\hline \multicolumn{6}{|l|}{ Cumulative chemotherapy received } \\
\hline \multicolumn{2}{|l|}{$>250 \mathrm{mg} \mathrm{vs} .<250 \mathrm{mg}$} & 0.506 & 0.742 & \multicolumn{2}{|l|}{1.832} \\
\hline \multicolumn{6}{|l|}{ Staging } \\
\hline II vs. III & & 0.439 & 0.766 & \multicolumn{2}{|l|}{1.847} \\
\hline \multicolumn{6}{|l|}{ Hemoglobin level } \\
\hline$<10 \mathrm{~g} \%$ vs. $>10 \mathrm{~g} \%$ & & 0.553 & 0.426 & \multicolumn{2}{|l|}{1.580} \\
\hline \multicolumn{6}{|l|}{ Platelets level } \\
\hline \multicolumn{2}{|c|}{$<400 \times 10^{9} /$ litre vs. $>400 \times 10^{9}$ /litre } & 0.004 & 1.290 & \multicolumn{2}{|l|}{3.784} \\
\hline
\end{tabular}

Sharma and Singh (14), Cheng et al. (15), in 2017, reported a positive correlation between thrombocytosis and poor outcome. We defined platelet count higher than $400 \times$ $10^{9} /$ liter as thrombocytosis in our study. In this regard, most of the studies have considered the same cut-off(Table 3). Our intention was to assess thrombocytosis as a prognostic factor in Indian patients with cervical carcinoma.

We observed thrombocytosis in $15.8 \%$ of the patients during diagnosis, which was similar to most of the published studies (4,10-12), except for one by Hernandez et al. (10) where it was $30 \%$.
Thrombocytosis was shown to be associated with advanced stages, bulky disease, and pelvic node positivity (1012). Only Lopes et al. did not show any association of thrombocytosis with nodal positivity because most of the patients had early-stage disease where the incidence of nodal metastasis was low $(11,12)$. As all our patients had locally advanced disease, we found no correlation of thrombocytosis with age, stage, and pre-treatment hemoglobin levels. We did not evaluate correlation with the nodal status. A study by Kawano et al. (12) and Kozasa et al. (16) showed an association of thrombocytosis with young age ( $<50$ years) 


\begin{tabular}{|c|c|c|c|c|c|c|c|}
\hline Study & $\begin{array}{c}\text { No. of } \\
\text { Patients }\end{array}$ & Treatment & $\begin{array}{l}\text { Platelet Level } \\
\text { Cut Off }\end{array}$ & $\begin{array}{l}\text { Incidence of } \\
\text { Thrombocy- } \\
\text { tosis }\end{array}$ & Results & Significance & $\begin{array}{c}\mathbf{P} \\
\text { Value }\end{array}$ \\
\hline Hernandez et al. (4) & 113 & $\begin{array}{l}\text { Radiotherapy } \\
\text { alone }\end{array}$ & $\begin{array}{l}>400 \times \\
10^{9} / \text { liter }\end{array}$ & $18 \%$ & $\begin{array}{l}\text { The 5-year-survival for } \\
\text { patients with normal } \\
\text { platelet counts was } \\
65 \% \text {, whereas it was } \\
25 \% \text { for patients with } \\
\text { thrombocytosis. }\end{array}$ & & $\begin{array}{c}< \\
0.0001\end{array}$ \\
\hline Hernandez et al. (10) & 294 & $\begin{array}{l}\text { Radiotherapy } \\
\text { and } \\
\text { concurrent } \\
\text { hydroxyurea } \\
\text { or } \\
\text { misonidazole }\end{array}$ & $\begin{array}{l}>400 \times \\
10^{9} / \text { liter }\end{array}$ & $30 \%$ & $\begin{array}{l}\text { Thrombocytosis had a } \\
55 \% \text { greater chance of } \\
\text { dying than those who } \\
\text { had a normal platelet } \\
\text { count. }\end{array}$ & $\begin{array}{l}\text { Risk ratio: } 1.5595 \% \\
\text { confidence interval: } \\
1.08-2.21\end{array}$ & 0.02 \\
\hline Lopes et al. (11) & 643 & $\begin{array}{l}\text { Surgery or } \\
\text { radiotherapy } \\
\text { with or } \\
\text { without } \\
\text { chemotherapy }\end{array}$ & $\begin{array}{l}>400 \times \\
10^{9} / \text { liter }\end{array}$ & $17 \%$ & $\begin{array}{l}\text { The 5-year survival rate } \\
\text { for patients with } \\
\text { thrombocytosis was } \\
57.1 \% \text {, which was } \\
\text { significantly worse } \\
\text { than the } 76.5 \% \text { for } \\
\text { those with normal } \\
\text { platelet counts. }\end{array}$ & $\begin{array}{l}\text { No significance on } \\
\text { multivariate analysis }\end{array}$ & $<0.01$ \\
\hline Kozasa et al. (16) & 684 & $\begin{array}{l}\text { Surgery or } \\
\text { radiotherapy } \\
\text { with or } \\
\text { without } \\
\text { chemotherapy }\end{array}$ & $\begin{array}{c}>400 \times \\
10^{9} / \text { liter }\end{array}$ & $12.7 \%$ & $\begin{array}{l}\text { Pre-treatment } \\
\text { thrombocytosis and } \\
\text { elevated PLR were } \\
\text { identified as } \\
\text { independent } \\
\text { predictors in cervical } \\
\text { cancer patients. }\end{array}$ & $\begin{array}{l}\text { Elevated platelet } \\
\text { count is a significant } \\
\text { predictor of outcome } \\
\text { on multivariate } \\
\text { analysis }\end{array}$ & \\
\hline
\end{tabular}

and low hemoglobin ( $<11 \mathrm{~g} \%)$, and only young age $(<50$ years); however, no such correlation was seen in any of the other studies, including our study. Our findings revealed that there is a significantly better response to treatment in patients without thrombocytosis in comparison to thrombocytosis group ( $\mathrm{P}$ value $\leq 0.001)$.

The patients with thrombocytosis had significantly poor OS and DFS of $41 \%$ and 39\%, respectively at 5 years in our study. A similar trend was seen in all of the studies with chemoradiation (Table 3) $(4,10-12,16)$. The first study by Hernandez et al., in 1992, showed a 5-year-survival advantage of $65 \%$ in non-thrombocytosis versus $25 \%$ in patients with thrombocytosis. Again in the year 2000, the same authors showed that patients with thrombocytosis had a $55 \%$ greater chance of dying than those who had a normal platelet count $(4,10)$. Kawano et al. also showed that patients with thrombocytosis had poor outcomes in terms of survival, with a hazard ratio of 1.65 for death (12). The recent study by Kozasa et al. showed an elevated platelet count was associated with poor OS and DFS. In addition, the au- thors showed elevated platelet/lymphocyte ratio was also associated with poor survival outcomes (16).

In our study, multivariate analysis showed that thrombocytosis is an independent prognostic factor (Table 3). Only Lopes et al. found no significant difference in survival when the patients were analyzed by the stage of the disease (11).

Irrespective of the platelet count at diagnosis, survival in young patients $(<45$ years $)$ is associated with poor outcome on multivariate analysis (Table 2), which is similar to the studies by Hernandez et al. (10), and Kawano et al. (12), who declared that the age less than 50 years was associated with poor outcome.

Most of the studies have shown that patients with thrombocytosis fail locally in comparison to systemically (12). The increased risk of local recurrence is probably due to poor response of the tumor to chemoradiation as seen in our study; also increased platelet counts have a role in stimulating tumor growth. However, platelet count may not influence the process of metastasis $(17,18)$. 
The drawback of our study is that it is a retrospective study and the results need to be verified in a prospective trial. The cut-off value for thrombocytosis is variable ranging from $350 \times 10^{9} /$ liter in Japanese studies to $>400 \times$ $10^{9} /$ liter in European studies. We considered a platelet count $>400 \times 10^{9} /$ liter to be the cut-off for this study similar to the most of the studies; however, there is no available confirming data regarding the same value for Indian patients. Nevertheless, to establish an optimal cut-off value for the platelets, we need larger and multicentral studies, containing patients from various ethnicities.

The data from our study and previous studies suggested that thrombocytosis could be a potential marker of prognosis, especially in patients with locally advanced and bulky diseases.

\subsection{Conclusions}

In conclusion, our study found thrombocytosis could be a potential prognostic marker in locally advanced cervical cancer treated with concurrent chemoradiation. We need further and larger prospective studies to categorize thrombocytosis as a prognostic factor for poor response.

\section{Footnotes}

Authors' Contribution: Nanda Ramanand: Developing the idea for the study and manuscript preparation; Shamsundar Sunkappa Dayashankara: Manuscript preparation, editing, and data collection; Aradhana Katke: Editing the manuscript and data collection; Thejaswini Boraiah helped to develop the idea for study and editing.

Conflict of Interests: The authors have no conflict of interest.

Financial Disclosure: The authors have no financial disclosure.

Funding/Support: No funding was received for this study.

\section{References}

1. Riess L. Zur pathologischen anatomic des blutes. Arch Anat Physiol Wissenschr Med.1872:39237-49.

2. Costantini V, Zacharski LR, Moritz TE, Edwards RL. The platelet count in carcinoma of the lung and colon. Thromb Haemost.1990;64(4):5015. doi: 10.1055/s-0038-1647347. [PubMed: 1964750].

3. Nakano T, Fujii J, Tamura S, Hada T, Higashino K. Thrombocytosis in patients with malignant pleural mesothelioma. Cancer. 1986;58(8):1699-701. doi: 10.1002/1097-0142(19861015)58:8<1699::AIDCNCR2820580820>3.0.CO;2-B. [PubMed: 3019510].

4. Hernandez E, Lavine M, Dunton CJ, Gracely E, Parker J. Poor prognosis associated with thrombocytosis in patients with cervical cancer. Cancer. 1992;69(12):2975-7. doi: 10.1002/10970142(19920615)69:12<2975::AID-CNCR2820691218>3.0.CO;2-A. [PubMed: 1591690].
5. Rodriguez GC, Clarke-Pearson DL, Soper JT, Berchuck A, Synan I, Dodge RK. The negative prognostic implications of thrombocytosis in women with stage IB cervical cancer. Obstet Gynecol. 1994;83(3):445-8. [PubMed: 8127540].

6. Pedersen LM, Milman N. Prognostic significance of thrombocytosis in patients with primary lung cancer. Eur RespirJ.1996;9(9):1826-30. doi: 10.1183/09031936.96.09091826. [PubMed: 8880098].

7. Zeimet AG, Marth C, Muller-Holzner E, Daxenbichler G, Dapunt O. Significance of thrombocytosis in patients with epithelial ovarian cancer. Am J Obstet Gynecol. 1994;170(2):549-54. doi: 10.1016/S00029378(94)70225-X. [PubMed: 8116711].

8. Levin J, Conley CL. Thrombocytosis associated with malignant disease. Arch Intern Med. 1964;114:497-500. doi: 10.1001/archinte.1964.03860100079008. [PubMed: 14184638].

9. Lin RJ, Afshar-Kharghan V, Schafer AI. Paraneoplastic thrombocytosis: The secrets of tumor self-promotion. Blood. 2014;124(2):184-7. doi: 10.1182/blood-2014-03-562538. [PubMed: 24868077]. [PubMed Central: PMC4093679].

10. Hernandez E, Donohue KA, Anderson LL, Heller PB, Stehman FB. The significance of thrombocytosis in patients with locally advanced cervical carcinoma: A Gynecologic Oncology Group study. Gynecol Oncol. 2000;78(2):137-42. doi:10.1006/gyno.2000.5838. [PubMed: 10926792].

11. Lopes A, Daras V, Cross PA, Robertson G, Beynon G, Monaghan JM. Thrombocytosis as a prognostic factor in women with cervical cancer. Cancer. 1994;74(1):90-2. doi: 10.1002/10970142(19940701)74:1<90::AID-CNCR2820740116>3.0.CO;2-0. [PubMed: 8004588].

12. Kawano M, Mabuchi S, Matsumoto Y, Sasano T, Takahashi R, Kuroda H, et al. Prognostic significance of pretreatment thrombocytosis in cervical cancer patients treated with definitive radiotherapy. Int J Gynecol Cancer. 2015;25(9):1656-62. doi: 10.1097/IGC.0000000000000533. [PubMed: 26332391].

13. Hernandez E, Heller PB, Whitney C, Diana K, Delgado G. Thrombocytosis in surgically treated stage IB squamous cell cervical carcinoma (A Gynecologic Oncology Group study). Gynecol Oncol. 1994;55(3 Pt 1):328-32. doi: 10.1006/gyno.1994.1300. [PubMed: 7835768].

14. Sharma D, Singh G. Thrombocytosis in gynecological cancers. J Cancer Res Ther. 2017;13(2):193-7. doi: 10.4103/0973-1482.189234. [PubMed: 28643732].

15. Cheng J, Zeng Z, Ye Q, Zhang Y, Yan R, Liang C, et al. The association of pretreatment thrombocytosis with prognosis and clinicopathological significance in cervical cancer: A systematic review and meta-analysis. Oncotarget. 2017;8(15):24327-36. doi: 10.18632/oncotarget.15358. [PubMed: 28212582]. [PubMed Central: PMC5421850].

16. Kozasa K, Mabuchi S, Komura N, Yokoi E, Hiromasa K, Sasano T, et al. Comparison of clinical utilities of the platelet count and plateletlymphocyte ratio for predicting survival in patients with cervical cancer: A single institutional study and literature review. Oncotarget. 2017;8(33):55394-404. doi: 10.18632/oncotarget.19560. [PubMed: 28903428]. [PubMed Central: PMC5589667].

17. Tuszynski GP, Nicosia RF. The role of thrombospondin-1 in tumor progression and angiogenesis. Bioessays. 1996;18(1):71-6. doi: 10.1002/bies.950180113. [PubMed: 8593167].

18. Arnoletti JP, Albo D, Granick MS, Solomon MP, Castiglioni A, Rothman VL, et al. Thrombospondin and transforming growth factor-beta 1 increase expression of urokinase-type plasminogen activator and plasminogen activator inhibitor-1 in human MDA-MB-231 breast cancer cells. Cancer. 1995;76(6):998-1005. doi: 10.1002/10970142(19950915)76:6<998::AID-CNCR2820760613>3.0.CO;2-0. [PubMed: 8625226] 